\title{
Türkiye’de İktisadi Gelişme Şoklarının İncelenmesi Üzerine Ampirik Bir Analiz
}

\section{An Empirical Analysis on Investigation of Economic Development Shocks in Turkey}

\author{
Sinan Erdoğan a,* \\ ${ }^{a}$ Dr Öğr. Üyesi., Hatay Mustafa Kemal Üniversitesi, İktisadi ve İdari Bilimler Fakültesi, İktisat Bölümü, 31060, Hatay/Türkiye. \\ ORCID: 0000-0003-3491-8234
}

\begin{tabular}{l} 
MAKALE BİLGİSİ \\
\hline Makale Geçmişi: \\
Başvuru tarihi: 31 Mart 2020 \\
Düzeltme tarihi: 10 Mayıs 2020 \\
Kabul tarihi: 14 Mayıs 2020 \\
\hline Anahtar Kelimeler: \\
İktisadi Gelişme \\
İktisadi Gelişme Şokları \\
Türkiye \\
Yapısal Kırılma \\
Birim Kök
\end{tabular}

ÖZ

Bu çalışmanın temel amacı, Türkiye ekonomisinde iktisadi gelişme şoklarının doğasını 1990-2018 dönemi için geleneksel ve yapısal kırılmalı birim kök ve durağanlık testleriyle araştırmaktır. Ampirik bulgular şöyle özetlenebilir: (a) geleneksel birim kök testi sonuçları iktisadi gelişmede görülebilecek şokların etkilerinin büyük oranda kalıcı olduğunu göstermektedir, (b) yapısal kırılmalı birim kök testleri sonuçları da iktisadi gelişme şoklarının etkisinin kalıcı olduğuna işaret etmektedir. Bu bulgular ışığında, Türkiye'de iktisadi gelişme üzerinde muhtemel şokların etkisinin kalıcı olduğu, bir diğer ifadeyle iktisadi gelişmenin herhangi bir şok durumunda dışsal müdahale olmaksızın ortalama değerine ve trend patikasına dönemediği ifade edilebilir. $\mathrm{Bu}$ bulgular, Türkiye'de iktisadi gelişme üzerinde dengeleyici politikaların gerekliliğine işaret etmektedir.

\section{ART ICLE INFO}

\section{Article history:}

Received 31 March 2020

Received in revised form 10 May 2020

Accepted August 14 May 2020

\section{Keywords:}

Economic Development

Economic development Shocks

Turkey

Structural Break

Unit Root

\begin{abstract}
A B S T R ACT
The main goal of this paper is to investigate nature of the economic development shocks in Turkey's economy from 1990 to 2018 by implementing set of unit root/stationarity tests. Empirical results are as follows: (a) According to the traditional unit root and stationarity tests results, the effects of shocks that can be seen in economic development are mostly permanent, (b) the results of unit root/stationarity tests with structural break indicate that the impact of economic development shocks is permanent. It can be said that the effects of possible shocks on economic development in Turkey are permanent, and economic development could not revert back its average and trend path without exogenous intervention. Therefore, stabilizing policies are required on economic development.
\end{abstract}

\section{Giriş}

Tarihsel süreç içerisinde iktisadi gelişmenin izlemiş olduğu dinamik patikanın anlaşılması azgelişmiş ve gelişmiş ülkeler için önemli olan bir husustur. Bu bağlamda iktisadi kalkınmanın dinamik seyrinin anlaşılması, diğer bir ifadeyle muhtemel şoklar karşısında iktisadi gelişmenin davranış dinamiklerinin ortaya konulması hem iktisadi hem de ampirik analiz bağlamında önemlidir. İlk olarak iktisadi açıdan durum ele alınacak olursa; iktisadi gelişme üzerinde görülebilecek bir şokun etkisi geçici ise, herhangi bir pozitif veya negatif şokun etkisi piyasa işleyişi ve dinamikleri çerçevesinde belirli bir süre içerisinde, herhangi bir dengeleyici müdahale olmaksızın ortadan kalkacaktır. Bu bağlamda piyasa işleyişine müdahale edilmemesi gerektiğini savunan klasik ve Neoklasik ekole dayalı iktisadi modellerin politik geri planında zımni bir durağanlık varsayımının olduğu ifade edilebilir. Diğer taraftan iktisadi gelişme üzerinde olası negatif veya pozitif bir şokun etkisi kalıcı ise, ilgili şokun etkisinin piyasa dinamikleri çerçevesinde müdahale olmaksızın giderilemediği, piyasa dinamiklerinin ilgili şokun etkisini

\footnotetext{
* Sorumlu yazar/Corresponding author

e-posta: phderdogan@gmail.com
} 
gidermekte başarısız olduğu söylenebilir. Böyle bir durumda dengeleyici bir dişsal müdahalenin gerekli olduğunu savunan Keynesyen temelli iktisadi modellerin geri planında ise zımni bir durağan olmayan süreç varsayımının olduğu söylenebilir. Dolayısıyla iktisadi gelişmenin zaman içindeki dinamik davranışının anlaşılması, iktisat politikası seçiminde önemli bir etkiye sahiptir.

İkinci olarak ampirik açıdan durum ele alınacak olursa, iktisadi gelişme serisinin durağan veya durağan olmayan bir süreç sergilemesi, ampirik tahmin yönteminin seçilmesi noktasında hayati öneme sahiptir. Söz gelimi iktisadi gelişme serisi ile beraber analize katılan diğer değişkenlerin durağan olmayan bir süreç sergilemesi, değişkenler arasında muhtemel bir eşbütünleşme ilişkisinin araştırılmasını gerektirmektedir. Bu noktada Engle-Granger (1987), Johansen-Juselius (Johansen, 1988, Johansen ve Juselius, 1990) gibi geleneksel eşbütünleşme testleri kullanılabilir olmaktadır. Açıklayıcı değişkenlerin entegrasyon derecesi $\mathrm{I}(0)$ ve I(1) olmak üzere karışı ike geleneksel eşbütünleşme yöntemleri kullanılabilir olmaktan çıkmakta, böyle bir durumda ARDL (autoregressive distributed lag) Sınır testi yaklaşımı (Pesaran ve Shin (1999); Pesaran vd. (2001)) gibi kimi açıklayıcı değişkenlerin entegrasyon derecelerinin farklı olmasına izin veren eşbütünleşme testleri kullanılabilmektedir (Erdogan vd. 2020). Son olarak değişkenler, düzey değerlerinde durağan bir süreç sergiliyorsa, durağan değişkenlerle tahmin yapmaya olanak sağlayan Granger Nedensellik testi (Granger, 1969) gibi yöntemler kullanılabilmektedir. Ayrıca Yılanci ve Tunalı (2014) bir değișkenin durağan bir süreç izlediği durumda geçmiş verileri kullanarak ilgili değişkenin gelecek dönemdeki seyri hakkında çıkarımlar yapılabileceğini, durağan olmayan bir süreç sergilemesi halinde ise mevcut verilerle değişkenin gelecek seyrine dair çıkarımlar yapmanın söz konusu olamayacağını belirtmektedir.

Ayrıca iktisadi gelişmede görülebilecek şokların yapısını anlamak, iktisadi gelişme şoklarının yayılma etkisi ile ekonominin tümünü etkilemesini önlemek, dengeleyici müdahale politikaları geliştirmek adına önemlidir. Söz gelimi iktisadi gelişmede görülebilecek bir şokun etkisi kalıcı olursa, bir diğer ifadeyle iktisadi gelişmenin durağan bir süreç izlemediği durumda, şokun etkisi doğrudan diğer makro iktisadi değişkenlere yayılabilecektir. Örneğin iktisadi gelişmenin gelir ayağında yaşanabilecek bir yavaşlama, toplam talep düşüşü kanalıyla üretim düşüşlerine ve işsizliğe neden olabilecektir. Tersine gelirde hızlı bir artış, konjonktürün genişleme safhasında toplam talebi artırmak koşuluyla kısa dönemde fiyat istikrarsızlıklarına neden olabilir. Diğer taraftan gelişmenin eğitim ayağında görülebilecek negatif bir şok, üretim ve teknoloji kullanım bilgisi ile donatılmış işgücü arzının düşmesine, bu durum ise işgücü piyasasında emek arz-talep dengesinin bozulmasına yol açabilir. $\mathrm{Bu}$ gibi hususlarda dengeleyici veya konjonktürün tersine iktisat politikalarının oluşturulması noktasında yaşanacak gecikmeleri önlemek adına iktisadi gelişmenin dinamik davranışını anlamak önemlidir.

Bu çalışmanın temel amacı Türkiye ekonomisinde 19902018 döneminde iktisadi gelişmenin dinamik davranışını geleneksel ve yapısal kırılmalı birim kök ve durağanlık testleri ile sınayarak, karşılaştırmalı bir analiz ile politika önerileri geliştirmek ve ilgili literatüre katkı yapmaktır. $\mathrm{Bu}$ bağlamda çalışmanın ikinci bölümü literatür tartışmasına, üçüncü bölümü çalışmada kullanılan veri, ampirik yöntem ve uygulama sonuçlarına, son olarak dördüncü bölüm ise sonuç ve tartışmaya yer vermektedir.

\section{Literatür Taraması}

Şenol (2009), 42 ülkede 1990-2015 Dönemi için iktisadi gelişmenin durağanlık özelliklerini CADF birim kök testi ile araştırmıştır. Çalışmadan elde edilen bulgulara göre iktisadi gelişme, gelişmekte olan ülkelerde durağan olmayan bir süreç sergilerken, gelişmiş ülkelerde ise durağan bir süreç sergilemektedir. Montañés ve Olmos (2014) İspanya'nın farklı bölgelerinde 1990-2010 döneminde insani gelişme endeksinin durağanlık özelliklerini genelleştirilmiş yapısal kırılmaları dikkate alan ve genelleştirilmiş en küçük kareler yöntemine dayalı birim kök testi ile araştırmışlardır. Çalışmadan elde edilen bulgular ağırlıklı olarak iktisadi gelişmenin durağan bir süreç izlemediği yönündedir.

Arslan vd. (2016) Türkiye'de 1975-2012 döneminde bebek ölüm oranlarını iktisadi gelişme göstergesi olarak kullandıkları çalışmasında, iktisadi gelişmenin dinamik seyrini Augmented Dickey-Fuller (ADF) ve Phillips-Perron (PP) birim kök testleriyle araştırmışlardır. Çalışmanın bulgularına göre bebek ölüm oranları, durağan olmayan bir süreç sergilemektedir. Erdem ve Çelik (2019) 33 Afrika ülkesinde 1995-2014 dönemi için insani gelişme endeksinin durağanlık özelliklerini yatay-kesit bağımlılığı dikkate alan panel birim kök (Smith Bootstrap) testi ile incelemiştir. Çalışmada elde edilen bulgulara göre ilgili ülkelerde iktisadi gelişme durağan olmayan bir süreç sergilemektedir. Güzel ve Erdoğan (2019) 1990-2017 dönemi için Türkiye'de iktisadi gelişmenin durağanlık özelliklerini Kwiatowski-Phillips-Schmidt-Shin (KPSS) durağanlık yaklaşımıyla incelemiş olup, elde edilen bulgulara göre Türkiye'de iktisadi gelişme durağan olmayan bir süreç sergilemektedir.

İktisadi gelişme olgusu yaklaşık üç çeyrek asırdır iktisat gündemindedir. Ancak insan odaklı yaklaşım bağlamında iktisadi gelişmenin durağanlık özelliklerinin araştırılması noktasında çok kısıtlı bir literatür olduğu göze çarpmaktadır. Türkiye özelinde yapılan çalışmalar ele alındığında, her ne kadar Türkiye'de iktisadi gelişmenin durağanlık özellikleri geleneksel birim kök ve durağanlık analizleri ile araştırılmış olsa da yapısal kırılmalar altında serinin dinamik seyrinin ne yönde değişeceği araştırılmamıştır. Yapısal kırılmaların dikkate alınmadığı durumda testlerde hesaplanan kritik değerler ve hipotez testleri sapmalı olabilmektedir (Perron, 1989). Bu nedenle çalışmada hem geleneksel hem de yapısal kırılmalı birim kök ve durağanlık testleri kullanılarak 1990-2018 dönemi için Türkiye'de iktisadi gelişmenin durağanlık özellikleri araştırılmıştır. Bu yönüyle çalışma literatürdeki benzer çalışmalardan ayrışmakta olup, daha kapsamlı ve mukayeseli bir analiz sunması yönleriyle literatüre katkı yapmayı amaçlamaktadır. 


\section{Veri, Yöntem ve Ampirik Uygulama}

\subsection{Veri}

Bu çalışmada Türkiye ekonomisinde iktisadi kalkınmada görülebilecek muhtemel şokların yapısı, 1990-2018 dönemi için Birleşmiş Milletler Kalkınma Programı (UNDP) tarafindan yıllık olarak yayınlanan İnsani Gelişme Endeksi (Human Development Index) verileri kullanılarak araştırılmış̧ır. İnsani gelişme endeksinin üç temel alt bileşeni bulunmakla beraber bunlar gelir, eğitim ve sağlık endeksleridir. Bu bağlamda gösterge, günümüzde iktisadi kalkınmayı ölçen kapsamlı göstergelerden birisi olması ve literatürde genel kabul görmesi nedeniyle iktisadi gelişme göstergesi olarak kullanılmış olup UNDP (2019) veri tabanından elde edilmiștir. Endeks 0 ile 1 arasında değişmekte, 0 en az gelişmişlik düzeyini, 1 ise en yüksek gelişmişlik düzeyini temsil etmektedir. 2018 yll itibariyle Türkiye'nin İnsani Gelişme Endeksi 0,791'dir. Türkiye, bu skor ile dünya sıralamasında 64 . sirada yer almaktadır. $\mathrm{Bu}$ bağlamda Türkiye, dünya ortalamasının üzerinde bir gelişmişlik skoruna sahiptir.

Grafik 1. Türkiye de İktisadi Gelişme Endeksinin (Logaritmik) Tarihsel Seyri

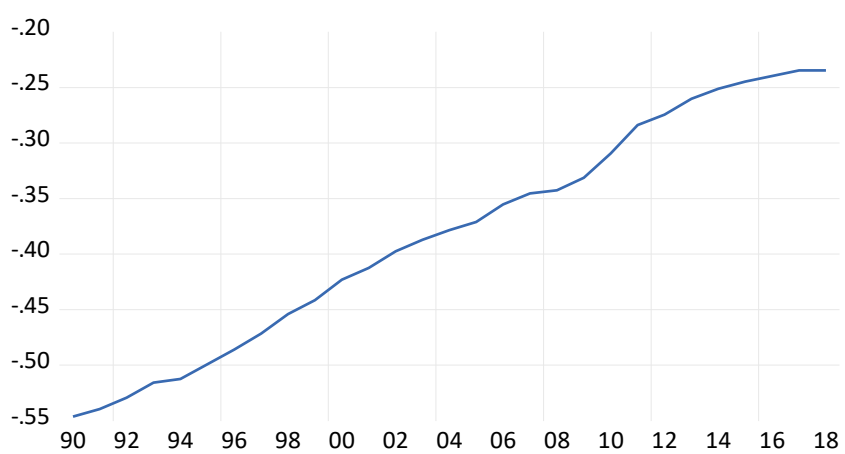

Not: Grafik yazar tarafindan oluşturulmuştur.

Türkiye'de insani gelişmenin tarihsel seyri Grafik 1'de gösterilmiştir. Grafikte de görüldüğü üzere, Türkiye'de iktisadi gelişme tarihsel olarak artış trendine sahiptir. Bu noktada dikkat çeken husus, bu artış davranışı belirli dönemler azalarak artan (1993-1994, 2000-2002, 20082010 gibi) bir seyre sahip iken, bazı dönemlerde ise artarak artan bir eğilime sahip olduğudur. Özellikle Türkiye Ekonomisinde iktisadi krizlerin, doğal afetlerin veya 2008 Mortgage krizi gibi uluslararası iktisadi krizlerin gerçekleştiği tarihler dikkate alındığında, serinin dinamik seyrinde yaşanan bu değişimlerin büyük oranda Türkiye ekonomisinin tarihsel gerçeklikleri ile de uyumlu olduğu sonucu çıkarılabilir.

\subsection{Yöntem}

Çalışmada iktisadi gelişmede görülebilecek şokların etkisinin geçici mi yoksa kalıcı mı olduğunu belirlemek adına öncelikle yapısal kırılmayı dikkate almayan, geleneksel birim kök ve durağanlık testleri olan Genişletilmiş Dickey-Fuller (1981) birim kök testi (ADF), Phillips ve Perron (1988) (PP) birim kök testi ve Kwiatkowski vd. (1992) tarafindan önerilen durağanlık testi (KPSS) kullanılmıştır. Bai ve Ng 'ye (2001) göre yokluk hipotezde durağanlığı test eden yöntemlerin kullanılması daha avantajlıdır. Çünkü yokluk hipotezinde durağanlığı test eden yaklaşımlarda durağanlık hipotezinin reddinin, yokluk hipotezinde birim kök görüşünün kıl payı reddedilemediği duruma kıyasla durağanlık aleyhine kanıtları daha da güçlendirdiğini belirtmiştir. $\mathrm{Bu}$ nedenle çalışmada sapmalı hipotez kabulünden kaçınmak adına yokluk hipotezinde birim kök ve durağanlığı test eden farklı test prosedürleri kullanılmıştır. ADF birim kök yaklaşımında kullanılan regresyon modeli şöyle tanımlanabilir (Enders, 2014: 218; Acaravcı vd. 2019: 8-9):

$\Delta y_{t}=\alpha_{0}+\gamma y_{t-1}+\alpha_{1} t+\sum_{i=1}^{p} \beta_{i} \Delta y_{t-i}+\varepsilon_{2 t}$

Burada $\alpha_{0}$, sabit; $\mathrm{t}$ doğrusal zaman trendi; $\Delta$, birinci sura fark1; $p$, gecikme sayısı ve $\varepsilon_{2 t}$ hata terimidir. ADF yaklaşımında yokluk hipotezinde "Birim kök vardır $(\gamma=0$ )" görüşü, "Seri durağandır $\gamma<0$ " görüşüne karşı test edilmektedir. Diğer taraftan Phillips-Perron (PP) (1988) birim kök testinin kullanmış olduğu veri tanımlama süreci aşağıdaki gibi tanımlanabilir:

$$
y_{t}=\delta y_{t-1}+u_{t}
$$

Burada PP testinin ADF spesifikasyonundan en temel fark 1 bağımlı değişkenin gecikmeli değeri fark operatörü ile değil, düzey değerleri ile kullanılmakta olup, iki numaralı denklem EKK yöntemi ile tahmin edilmekte ve sabit parametresi veya sabit-trend parametreleri de dahil edilerek genişletilebilmektedir. Aynı zamanda parametre katsayıları için hesaplanan kritik değerler, otokorelasyona karş1 düzeltilmiş kritik değerlerdir. Son olarak $u_{t}$, hata terimini ifade etmektedir. PP yaklaşımında da ADF yöntemine benzer biçimde yokluk hipotezinde "birim kök vardır" görüşü alternatif hipotezde "seri durağandır" görüşüne karşı test edilmektedir. Diğer taraftan KPSS durağanlık testinin kullanmış olduğu regresyon modeli aşağıdaki gibi tanımlanabilir (Kwiatkowski vd., 1992: 161):

$y_{t}=\delta t+r_{t}+\varepsilon_{3 t}$

Burada $r=r_{t-1}+u_{t} \quad$ ve $\mathrm{u}_{\mathrm{t}} \sim$ iid $\left(0, \sigma_{\mathrm{u}}^{2}\right)$ ve $\quad \varepsilon_{\mathrm{t}} \sim$ iid $\mathrm{N}\left(0, \sigma^{2}\right)$ dir. Ayrica $t$, deterministik trend parametresini, $r$ rassal süreci (random walk) ve $\varepsilon_{3 t}$, durağan hata terimini ifade etmektedir. KPSS yaklaşımında ADF yönteminden farklı olarak yokluk hipotezi; sabitli modelde $\sigma_{\mathrm{u}}{ }^{2}=0$, "seri ortalama durağandır" biçiminde, sabitli ve trendli modelde ise "seri trend durağandır" şeklinde önerilmiştir.

Diğer taraftan serilerde görülebilecek olası yapısal kırılmalar dikkate alınmadığı takdirde yokluk hipotezleri olması gerekenden aşırı biçimde kabul edilebilmektir. Bu nedenle birim kök (durağanlık) hipotezi, durağanlık (birim kök) hipotezi yerine kabul edilebilmektedir (Perron, 1989). Böyle bir durumda değişkenlerin dinamik seyri ile ilgili sapmalı hipotez testlerine bağlı olarak yanlış politika çıkarsamaları veya uygulamaları yapılabilmektedir (Erdogan ve Acaravci, 2019). Bu çalışmada sapmalı hipotez testi ve politika önerilerinden kaçınmak adına serilerde muhtemel oluşabilecek yapısal kırılmaları da göz önünde bulundurmaya olanak sağlayan, Zivot ve Andrews (1992) tarafindan önerilen ADF tipi tek kırılmalı yapısal kırılmalı 
birim kök testi ile Kurozumi (2002) tarafindan önerilen KPSS tipi tek kırılmalı durağanlık testi de kullanılmıştır.

Zivot ve Andrews (1992) tarafindan önerilen yapisal kırılmalı birim kök testi, temelde ADF spesifikasyonuna dayanmakla beraber yokluk hipotezinde " $T b$ tarihinde yapısal kırlma ile beraber birim kök vardır” görüşünü alternatif hipotezde "seri durağandır" görüşüne karşı test etmektedir. Çalışma kapsamında kullanılan sabitte kırılma ve sabit ve trendde kırılmalı modeller sırasıyla denklem 5 ve 6'daki gibidir:

$$
\begin{aligned}
& y_{t}=\alpha+d D\left(T_{B}\right)_{t}+y_{t-1}+e_{t} \\
& y_{t}=\alpha_{1}+d D\left(T_{B}\right)_{t}+y_{t-1}+\left(\alpha_{2}-\alpha_{1}\right) D U_{t}+e_{t}
\end{aligned}
$$

Burada $D\left(T_{B}\right)_{t}=1 \quad$ ve $t=T_{B}+1,0$ diğer; $D U_{t}=1 \quad$ ve $t>T_{B}, 0$ diğer; $A(L) e_{t}=B(L) v_{t}, v_{t} \equiv i i d\left(0, \sigma^{2}\right) \quad$ olup, burada $A(L)$ ve $B(L)$ sirasıyla gecikme operatöründe $p$ ve $q$ dereceden polinomiallerdir. 4 ve 5 numaralı denklemleri sabit ve trendde değişimleri de içerecek şekilde genişletilirse sırasıyla denklem 6 ve 7'deki hale gelecektir:

$$
\begin{aligned}
& y_{t}=\alpha+\theta D U_{t}+\beta_{t}+d D\left(T_{B}\right)_{t}+\rho y_{t-1}+\sum_{i=1}^{k} \varphi \Delta y_{t-j}+e_{t} \\
& y_{t}=\alpha_{1}+\theta D U_{t}+\beta_{t}+d D\left(T_{B}\right)_{t}+\tau D T_{t}^{*}+\rho y_{t-1}+\sum_{j=1}^{k} \varphi \Delta y_{t-j}+e_{t}
\end{aligned}
$$

Kurozumi (2002) tarafindan önerilen tek kırılmalı durağanlık testi temelde KPSS testi stratejisine dayanmakta olup, test kapsamında kullanılan veri üretme süreci şöyle tanımlanabilir:

$$
y_{t}=z_{t}^{\prime} \beta+x_{t}
$$

Burada $x_{t}=r_{t}+u_{t} \quad r_{t}=r_{t 1}+\varepsilon_{t}$ ve $u_{t}=\sum_{j=0}^{\infty} \phi_{j} t_{t-j}$ 'dir. $z_{t}$ trendde kırılmayı içeren deterministtik bileşen ve $\left\{l_{t} \varepsilon_{t}\right\} \square$ iid 'dir. Burada yapısal kırılmanın $T_{s}\left(1<T_{B}<T\right)$ tarihinde gerçekleştiği ve fraksiyonun $\omega=T_{B} / T$ biçiminde sabit olduğu varsayılmaktadır. 8 numaralı denklemde sabitte kırılma $z_{t}=\left[1, D U_{t}\right]$, sabit ve trendde kırılma ise $z_{t}=\left[1, D U_{t}, t / T, D T_{t}\right]$ biçiminde ifade edilebilir. Burada $D U_{t}=1\left(t>T_{B}\right) \quad$ ve $\quad D T_{t}=1\left(t>T_{B}\right) \times\left(t-T_{B}\right) / T$ 'dir Burada yokluk hipotezi $H_{0}: \sigma_{\varepsilon}^{2}=0$ "Yapısal kırılma ile seri durağandır" iken alternatif hipotez ise "yapısal kırılma ile seri durăgan değildir" biçimindedir.

\subsection{Ampirik Bulgular}

Çalışma kapsamında uygulanan geleneksel birim kök testi ve durağanlık test sonuçları Tablo 1' de sunulmuştur. Bu bağlamda ADF ve PP birim kök testi sonuçlarına göre Türkiye ekonomisinde iktisadi gelişme hem sabitli hem de sabitli ve trendli modelde durağan değildir. KPSS test sonuçlarına göre ise iktisadi kalkınma sabitli modelde durağan değilken, sabitli ve trendli modelde ise durağandır. $\mathrm{Bu}$ bağlamda yapısal kırılmalar göz ardı edildiği durumda uygulanan testlere göre Türkiye' de iktisadi kalkınma, 1990-
2018 dönemi için durağan değildir. Dolayısıyla bulgulara

\begin{tabular}{|c|c|c|c|c|c|c|}
\hline & \multicolumn{2}{|c|}{ ADF } & \multicolumn{2}{|c|}{$\mathbf{P P}$} & \multicolumn{2}{|c|}{ KPSS } \\
\hline & c & $(c+t)$ & c & $(c+t)$ & c & $(c+t)$ \\
\hline$h d i$ & $\begin{array}{l}-1,073 \\
(0,711)\end{array}$ & $\begin{array}{l}-1,564 \\
(0,780)\end{array}$ & $\begin{array}{l}-0,952 \\
(0,755)\end{array}$ & $\begin{array}{c}-1,472 \\
(0,815)\end{array}$ & $0,684 * *$ & 0,083 \\
\hline & & & & & 0.463 & 0.146 \\
\hline \multicolumn{7}{|c|}{$\begin{array}{l}\text { Not: Birim kök testlerinde kullanılan modeller: "c+t, trend ve sabiti } \\
\text { içerir"; "c, sadece sabiti içerir" şeklindedir. Parantez içerindeki değerler, } \\
\text { olasılık değerleridir. ADF testi için en uygun gecikme sayısı seçiminde, } \\
\text { Schwarz-Bayesian Bilgi Kriteri (SBC); PP ve KPSS testi için, Newey- } \\
\text { West düzeltme gecikmesi seçeneği kullanılarak en uygun gecikme sayıs } \\
\text { kullanılmıştır. **: } \% 5 \text { seviyesinde istatistiksel olarak anlamlılığı ifade } \\
\text { etmektedir. }\end{array}$} \\
\hline
\end{tabular}
göre iktisadi gelişme de görülebilecek herhangi bir şokun etkisi kalıcı olmakta, değişken dişsal bir müdahale olmaksızın ortalama değerine dönememektedir.

Tablo 1. Geleneksel Birim Kök Testleri Sonuçları

Yapısal kırılmaların dikkate alındığı birim kök ve durağanlık testi sonuçları Tablo 2 (Model A: Sabitte Kırılma) ve Tablo 3 (Model C: Sabitte ve Trendde Kırılma)' de sunulmuştur. Elde edilen bulgulara göre Türkiye'de iktisadi gelişme, hem tek kırılmalı ADF birim kök hem de tek kırılmalı KPSS durağanlık testi sonuçlarına göre birim kök içermektedir. Bu bağlamda yapısal kırılmalı testlerden elde edilen bulgular, geleneksel testlerden elde edilen bulguları büyük oranda desteklemektedir. Dolayısıyla iktisadi gelişmede görülebilecek muhtemel bir şokun etkisi kalıcı olabilecek, herhangi bir müdahale olmaksızın denge patikasına geri dönemeyecektir. Ayrıca yapısal kırılma tarihleri irdelenecek olursa tek kırılmalı ADF testinden elde edilen kırılma tarihleri 1998 ve 2009 iken, tek kırılmalı KPSS testinden elde edilen kırılma tarihlerinin 2010 ve 2014 yılı olduğu görülmektedir. Bu bağlamda Türkiye'de iktisadi gelişmede yapısal kırılmanın gerçekleştiği yıl olarak 2008-2010 arası dönem kabul edilebilir. Türkiye ekonomisinde iktisadi gelişmenin dinamik seyri incelendiğinde (Grafik 1), 2008 yılından itibaren iktisadi gelişmenin azalan oranda bir artış trendine girdiği, yani serinin trend eğiminin azaldığı ve bu durumun 2010 yılına kadar devam ettiği söylenebilir. Dolayısıyla ilgili dönemde yapısal kırılmanın gerçekleştiğinin kabul edilmesi, serinin dinamik seyri ile de uyumlu olduğu ifade edilebilir. Ayrıca bu dönemin Amerika Birleşik Devletleri'nde patlak veren Mortgage Krizi'nin dünya iktisadi sistemine yayıldığı zaman dilimi olduğu ve ilgili dönemde Türkiye ekonomisinde ciddi ölçüde bir milli gelir kaybı yaşandığ1 göz önünde bulundurulduğunda, yapısal kırılma tarihlerinin ilgili aralıkları işaret etmesinin hem ulusal hem de uluslararası iktisadi gerçeklerle de uyumlu olduğu söylenebilir.

Tablo 2. Yapısal Kırılmalı Test Sonuçları (Sabitte Kırılma)

\begin{tabular}{lccc}
\hline \multirow{2}{*}{ Test } & \multicolumn{3}{c}{ Model A: Sabitte Kurılma } \\
\cline { 2 - 4 } & İstatistik & $\begin{array}{c}\text { Fraksiyon } \\
(\boldsymbol{\lambda})\end{array}$ & $\begin{array}{c}\text { Kurılma } \\
\text { Tarihi }\end{array}$ \\
\hline $\begin{array}{l}\text { Zivot- } \\
\text { Andrews }\end{array}$ & $-1,962$ & 0,310 & 1998 \\
$\begin{array}{l}(1992) \\
\text { Kurozumi } \\
(2002)\end{array}$ & $0,046 * *$ & 0,025 & \\
\hline
\end{tabular}

Kritik Değerler (\%5): Model A Zivot-Andrews (1992): -4,80,

Model A Kurozumi (2002): 0,027; Model C Zivot-Andrews 
(1992):: -5,08, Model C Kurozumi (2002): 0,015. **:\%5 seviyesinde istatistiksel olarak anlamlılığı ifade etmektedir.

Tablo 3. Yapısal Kırılmalı Test Sonuçları (Sabitte ve Trendde Kırılma)

\begin{tabular}{|c|c|c|c|}
\hline \multirow[b]{2}{*}{ Test } & \multicolumn{3}{|c|}{ Model C: Sabit ve Trendde Kırılma } \\
\hline & İstatistik & 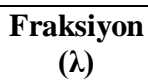 & $\begin{array}{c}\text { Kirılma } \\
\text { Tarihi }\end{array}$ \\
\hline $\begin{array}{l}\text { Zivot- } \\
\text { Andrews } \\
\text { (1992) }\end{array}$ & $-2,604$ & 0,690 & 2009 \\
\hline $\begin{array}{l}\text { Kurozumi } \\
\text { (2002) }\end{array}$ & $0,031 * *$ & 0,724 & 2010 \\
\hline
\end{tabular}

Not: Açıklamalar için bkz. Tablo 2

\section{Sonuç ve Tartışma}

İktisadi gelişme, literatürde genellikle azgelişmiş ülkeler özelinde değerlendirilen bir konudur. İktisadi refahı artırmak adına uluslararası iktisadi ve politik rekabetin günümüzde ne denli sertleşebildiği göz önünde bulundurulduğunda, iktisadi gelişmenin hızlandırılmasının salt azgelişmiş ülkelerin değil aynı zamanda gelişmiş ülkelerin de temel hedefleri arasında olduğu ifade edilebilir. En yalın ifadesiyle bireylere müreffeh yaşam koşulları sunmak, iktisat politikalarının temel amaçları arasında yer almaktadır. Bu noktada etkin iktisadi gelişme politikalarının oluşturulması, oluşabilecek muhtemel şokların doğasının anlaşılması, karşı konjonktür oluşturabilecek politikaların belirlenmesi ve iktisadi gelişmenin gelecek dönemlerde seyrinin anlaşılabilmesi adına iktisadi gelişmenin durağanlık özelliklerinin anlaşılması önem kazanmaktadır. Bu çalışmada Türkiye'de iktisadi gelişmenin dinamik seyri 1990-2018 dönemi için geleneksel ve yapısal kırılmalı birim kök ve durağanlık yaklaşımları ile test edilmiştir. Hem geleneksel hem de yapısal kırılmalı testlerden elde edilen bulgulara göre Türkiye'de iktisadi gelişme durağan bir sürece sahip değildir. Bir diğer ifadeyle muhtemel bir şok karşısında iktisadi gelişme, dışsal bir müdahale olmaksızın denge değerlerine piyasa dinamikleri çerçevesinde geri gelmemekte, tarihsel ortalama ve trend patikasından sapmaktadır.

Türkiye ekonomisinde muhtemel şokların etkisinin kalıcı olması, bu noktada karşı konjonktür oluşturabilecek politikaların seçimi ve uygulanmasını önemli hale getirmektedir. Özellikle insani gelişme endeksinin temel bileşenleri olan gelir, eğitim ve sağlık gibi göstergelerde yaşanabilecek bozulmaların kolaylıkla diğer makro iktisadi değişkenlere yayılabileceği göz önüne alındığında, Türkiye ekonomisinde reaktif politika seçimlerinden ziyade proaktif politika seçimi önem kazanmaktadır. Bir diğer ifadeyle karar alıcılar gelişme şokları gerçekleştikten sonra şokun nedenlerini tespit etmek yerine, mevcut ortalama değeri ve trend patikasının sürdürülebilmesi adına şok gerçekleşmeden önce dengeleyici tedbirler almalı ve dalgalanmaya neden olan iktisadi aksaklıkların çözümü için gerekli politikaları uygulamalıdır.

Son olarak bu çalışmada endeksin kapsadığı zaman dilimin göreli olarak kısa olması nedeniyle tek kırılmaya izin veren birim kök ve durağanlık testleri kullanılmıştır. Endeksin zaman boyutunun uzaması; birden fazla kırılmaya izin veren ve ilgili dönemin iktisadi dinamiklerinin daha detaylı yakalanmasına olanak sağlayan yöntemlerin kullanılabilmesinin önünü açacak ve geleneksel, tek veya çok kırılmalı testlerden elde edilen bulguların güvenilirliğini artıracaktır. $\mathrm{Bu}$ nedenle endeksin zaman boyutunun uzaması ile beraber, gelecek çalışmalarda Türkiye ekonomisinde iktisadi gelişme şoklarının yapısının çoklu kırılmaya olanak sağlayan yaklaşımlarla araştırılması önemlidir.

\section{Kaynakça}

Acaravcı, A., Akalin, G. ve Erdoğan, S. (2019). AraştırmaGeliştirme Harcamalarının Türkiye İhracatına Etkileri. Hacettepe Üniversitesi İktisadi ve İdari Bilimler Fakültesi Dergisi, 37(1), 1-16.

Arslan, İ., Eren, M. V. ve Kaynak, S. (2016). Sağlık ile Kalkınma Arasındaki İlişkinin Asimetrik Nedensellik Analizi. Dokuz Eylül Üniversitesi İktisadi Idari Bilimler Fakültesi Dergisi, 31(2), 287-310.

Bai, J. ve Ng, S. (2005). A new look at panel testing of stationarity and the PPP hypothesis (pp. 426-450). Cambridge University Press.

Dickey, D. A. ve Fuller, W. A. (1981). Likelihood ratio statistics for autoregressive time series with a unit root. Econometrica: journal of the Econometric Society, 1057-1072.

Enders, W. (2014), Applied Econometric Time Series, 4. Baskı, USA: John Wiley\&Sons, Inc.

Engle, R. F. ve Granger, C. W. (1987). Co-integration and error correction: representation, estimation, and testing. Econometrica: journal of the Econometric Society, 251-276.

Erdem, E. ve Çelik, B. (2019). İnsani Gelişme ve Ekonomik Büyüme İlişkisi: Bazı Afrika Ülkeleri Üzerine Bir Uygulama. Bingöl Üniversitesi Sosyal Bilimler Enstitüsü Dergisi, 9(17), 13-36.

Erdogan, S. Ve Acaravci, A. (2019). Revisiting the convergence of carbon emission phenomenon in OECD countries: new evidence from Fourier panel KPSS test. Environmental Science and Pollution Research, 26(24), 24758-24771.

Erdogan, S., Akalin, G. ve Oypan, O. (2020). Are Shocks to Disaggregated Energy Consumption Transitory or Permanent in Turkey? New Evidence from Fourier Panel KPSS Test. Energy, 117174.

Granger, C. W. (1969). Investigating causal relations by econometric models and cross-spectral methods. Econometrica: journal of the Econometric Society, 424-438.

Güzel, A. E. ve Erdoğan, S. (2019). Demokrasi, Gelir Eşitsizliği ve İnsani Gelişme İlişkisi: Türkiye Örneği. in Congress Proceedings Series (p. 233-241).

Johansen, S. (1988). Statistical analysis of cointegration vectors. Journal of economic dynamics and control, 12(2-3), 231-254.

Johansen, S. ve Juselius, K. (1990). Maximum likelihood estimation and inference on cointegration-with 
applications to the demand for money. Oxford Bulletin of Economics and statistics, 52(2), 169-210.

Kurozumi, E. (2002). Testing for stationarity with a break. Journal of Econometrics, 108(1), 63-99.

Kwiatkowski, D., Phillips, P. C., Schmidt, P. ve Shin, Y. (1992). Testing the null hypothesis of stationarity against the alternative of a unit root. Journal of econometrics, 54(1-3), 159-178.

Montañés, A. ve Olmos, L. (2014). Do the Spanish regions converge? A unit root analysis for the HDI of the Spanish regions. Applied Economics, 46(34), 42184230.

Perron, P. (1989). The great crash, the oil price shock, and the unit root hypothesis. Econometrica: journal of the Econometric Society, 1361-1401.

Pesaran, M. H. ve Shin, Y. (1998). An autoregressive distributed-lag modelling approach to cointegration analysis. Econometric Society Monographs, 31, 371413.
Pesaran, M. H., Shin, Y. ve Smith, R. J. (2001). Bounds testing approaches to the analysis of level relationships. Journal of applied econometrics, 16(3), 289-326.

Phillips, P. C. ve Perron, P. (1988). Testing for a unit root in time series regression. Biometrika, 75(2), 335-346.

Şenol, Z. (2019). Finansal Gelişim İle İnsani Gelişim Arasındaki İlişki: Gelişmiş Ve Gelişmekte Olan Ülkeler Örneği. Uluslararası Yönetim Iktisat ve İşletme Dergisi, 15(2), 341-358.

UNDP (2019). Human Development Data. http://hdr.undp.org/en/data (Erişim Tarihi: 30. 09. 2019).

Yilanci, V. ve Tunali, Ç. B. (2014). Are fluctuations in energy consumption transitory or permanent? Evidence from a Fourier LM unit root test. Renewable and Sustainable Energy Reviews, 36, 20-25.

Zivot, E. ve Andrews, D. W. K. (2002). Further evidence on the great crash, the oil-price shock, and the unitroot hypothesis. Journal of business \& economic statistics, 20(1), 25-44. 